\title{
Design Science Research e Pesquisas com os Cotidianos Escolares para fazerpensar as pesquisas em Informática na Educação
}

\author{
Mariano Pimentel \\ Departamento de Informática Aplicada \\ Universidade Federal do Estado do Rio de Janeiro (UNIRIO) - RJ - Brasil \\ pimentel@uniriotec.br
}

\begin{abstract}
In this paper, following an autobiographical research methodology, I tell my academic history in the pursuit of conducting and guiding rigorous researches on computers in education. I illustrate my narrative by citing my publication history in the SBIE, the WIE and in the RBIE. I also present the reasons that led me to adopt the epistemological paradigms Design Science Research and the Everyday Life Studies. By telling my academic history, I aim at demonstrating the importance of discussing the epistemological presuppositions of our research work, what can contribute to an increase in the quality of the work done by the community of Brazilian scholars that focus on computers in education.
\end{abstract}

Resumo. Neste artigo, com base no método "história de vida autobiográfica", conto minha história em busca de um modo de realizar e orientar pesquisas rigorosas na área de Informática na Educação. Ilustro minha narrativa com dados do meu histórico de publicações no SBIE, WIE e RBIE. Revelo os motivos que me fizeram adotar os paradigmas epistemológicos Design Science Research e Pesquisas com Cotidianos Escolares. Com essa minha história, objetivo mostrar a importância de discutirmos os pressupostos epistemológicos de nossas pesquisas, o que pode aumentar a qualidade das produções de nossa comunidade de pesquisa em Informática na Educação.

\section{O que é e como se faz pesquisa em Informática na Educação?}

Todos nós, pesquisadores que publicamos no $\mathrm{SBIE}^{1}, \mathrm{WIE}^{2}$ e $\mathrm{RBIE}^{3}$ (eventos e periódico promovidos pela $\mathrm{SBC}^{4}$ ), já nos questionamos como fazer pesquisas em Informática na Educação. Tentar responder essa questão implica em questionarmos as diferentes possibilidades para fazerpensar ${ }^{5}$ uma pesquisa científica. Esboçar algumas respostas,

\footnotetext{
${ }^{1}$ Simpósio Brasileiro de Informática na Educação - http://www.br-ie.org/pub/index.php/sbie

${ }^{2}$ Workshop de Informática na Escola - http://www.br-ie.org/pub/index.php/wie

${ }^{3}$ Revista Brasileira de Informática na Educação - http://www.br-ie.org/pub/index.php/rbie

${ }^{4}$ Sociedade Brasileira de Computação - http://www.sbc.org.br

5 Como praticado nos relatos das Pesquisas com os Cotidianos Escolares, esses termos foram aqui grafados juntos para indicar a não-separação entre o fazer e o pensar, uma licença ortográfica para desconstruir as dicotomias que organizaram o pensamento das ciências na Modernidade.
} 
ainda que provisórias, nos possibilita refletir sobre o que podemos melhorar nas pesquisas que realizamos, bem como (re)pensar nossas pesquisas nos próximos anos.

Neste artigo, conto como minha prática de pesquisa científica foi se transformando nas últimas décadas, e discuto as abordagens epistemológicasmetodológicas que eu e o grupo de pesquisa que coordeno nos apropriamos para fazerpensar as pesquisas em Informática na Educação na atualidade. Para ilustrar este relato, trago alguns dados do meu histórico de publicações no SBIE, WIE e RBIE.

O presente relato baseia-se no método "história de vida autobiográfica":

Escreve Becker (1986) que a autobiografia proporcionada pela técnica de história de vida se propõe a nos contar a vida de um ser engajado; há um esforço em manter uma coerência entre a história que ele narra e aquilo que uma investigação objetiva quer descobrir. (...) Reafirmando o caráter ao mesmo tempo fenomenológico e científico do recurso metodológico da história de vida, Becker (1986) observa que a biografia narrada pode ser particularmente útil para esclarecer o lado subjetivo de processos institucionais. (...) Na elaboração de Ferraroti (1983), se cada sujeito representa a reapropriação singular do universo social e histórico que o envolve, podemos ter a pretensão de conhecer o social a partir da especificidade de uma práxis individual. De fato, para o autor, cada sujeito totaliza a sociedade pela mediação de seu contexto social mais próximo, isto é, dos grupos específicos do qual faz parte em seu dia-a-dia. (Macedo, 2006, p.111-113)

Narro aqui minhas experiências e reflito sobre minha itinerância em busca de um modo para realizar e orientar pesquisas rigorosas em Informática na Educação. Ao refletir sobre minhas lutas e conflitos em busca da constituição de minha identidade enquanto pesquisador-orientador nessa área (uma identidade sempre fluida e em constante reconstrução), busco mostrar a importância de discutirmos os pressupostos epistemológicos de nossas pesquisas científicas, e com essa indicação espero contribuir para o aumento da qualidade das produções científicas de nossa comunidade.

\section{Desenvolver sistemas computacionais não é fazer pesquisa científica!}

Minhas primeiras publicações datam da década de 1990, ainda na infância do SBIE e do WIE. Nelas apresentei os sistemas computacionais que desenvolvi durante minha Iniciação Científica em Informática. Devo confessar que, hoje, percebo minhas pesquisas daquela década como sendo "fiz algo novo, eis meu produto", conforme caracterizado por Wazlawick (2008). Concordando com esse autor, percebo que meus artigos eram parecidos com uma propaganda do produto desenvolvido. Naquela época, fazer pesquisa em Informática na Educação era, para mim, conceber produtos computacionais considerando as teorias de aprendizagem e desenvolver uma "prova de conceito" (PROVA, 2016) para mostrar que a proposta era implementável, e isso era suficiente para a comunidade considerar a pesquisa publicável.

No primeiro artigo que publiquei no SBIE (Pimentel e Souza, 1996), apresentei um sistema computacional para apoiar o aprendizado de Algoritmos e Grafos: "Esse ambiente é a associação de um laboratório de algoritmos com um hipertexto da matéria" (idem, p.15). Naquele artigo, apresentei várias telas justificando as "bases pedagógicas 
VI Congresso Brasileiro de Informática na Educação (CBIE 2017)

Anais do XXVIII Simpósio Brasileiro de Informática na Educação (SBIE 2017)

do projeto" de acordo com estudos em psicopedagogia mais difundidos em nossa comunidade naquela época.

Já no primeiro artigo que publiquei no WIE (Pimentel, 1998), apresentei o software educacional que estava desenvolvendo para o meu Trabalho de Conclusão de Curso de Graduação. Muito orgulhoso, apresentei algumas das telas que havia criado com muito capricho e justificava minhas escolhas argumentando como aquele produto era lúdico e alinhado aos princípios construtivistas.

Custei a compreender que desenvolver sistemas computacionais não é fazer pesquisa científica. Uma incompreensão também apoiada pela maneira como os eventos e periódico de nossa comunidade são apresentados: "O SBIE prioriza trabalhos que apresentem a concepção, o desenvolvimento e a avaliação de soluções das Tecnologias Digitais da Informação e da Comunicação para promoção da aprendizagem" (SBIE, 2017); “Os principais objetivos da revista são: (...) divulgar produtos de Informática aplicáveis à educação" (RBIE, 2017). Essa confusão entre desenvolver um artefato e fazer uma pesquisa científica me perseguiu por muitos anos. Uma confusão que assombra muitos pesquisadores em computação:

Em computação, os termos ciência e tecnologia quase sempre andam tão juntos que muitas pessoas têm dificuldade em distingui-los. (...) Observa-se que, algumas vezes, dissertações e teses em computação, bem como artigos científicos, ainda são fortemente caracterizados como apresentações meramente tecnológicas: sistemas, protótipos, frameworks, arquiteturas, modelos, processos, todas essas construções são técnicas, e não necessariamente ciência. (Wazlawick, 2008)

Essa confusão se transformou em um dilema que busquei compreender ao longo de toda a minha formação e carreira enquanto pesquisador-orientador, e com o presente artigo revelo que ainda venho enfrentando tal questão. Nas próximas seções, conto como minha práxis foi se modificando durante minha busca por um modo de fazerpensar pesquisa por meio do desenvolvendo de tecnologias computacionais e que, ao mesmo tempo, eu reconhecesse como científica.

\section{Método de Pesquisa Científica: parecia ser a resposta definitiva...}

Foi no início da década de 2000, cursando o mestrado, que compreendi a noção de pesquisa aplicada e empírica. Naquela época, a Internet estava se popularizando e em nossa área proliferavam as pesquisas voltadas para o desenvolvimento das tecnologias digitais em rede, com especial interesse para a educação a distância e os ambientes virtuais de aprendizagem como TeleEduc e AulaNet. Agarrei a oportunidade de cursar uma disciplina a distância, intitulada "Tecnologia de Informação Aplicada a Educação (TIAE)" (Fuks et al., 2001). Fiquei muito impactado pela ênfase dada naquela disciplina para a discussão em grupo e a autoria, contrastando com as práticas expositivas que eu estava acostumado nas disciplinas presenciais. Curtia especialmente as sessões de batepapo que realizávamos semanalmente e, no trabalho final da disciplina, discuti o problema da confusão que eu sentia ao tentar acompanhar a conversação pelo bate-papo. Havia identificado um problema! Debrucei-me sobre os registros de bate-papo para analisar a frequência com que o problema havia sido manifestado ao longo das 13 sessões daquela disciplina. Cheguei a desenvolver um método de análise do registro de bate-papo, que publiquei no SBIE (Sampaio e Pimentel, 2000), o que me rendeu o 
prêmio de $3^{\circ}$ melhor artigo, que, por sua vez, resultou em um convite para a submissão de uma versão estendida na RBIE (Pimentel e Sampaio, 2002), meu primeiro artigo publicado em um periódico. Propus uma solução para resolver o problema: encadear as mensagens no bate-papo, tal como fazíamos nos fóruns de discussão, pois assim ninguém se perderia na conversação. Como prova de conceito, desenvolvi o sistema "HiperDiálogo". Neste ponto, pensava que estava com tudo pronto para escrever e defender a dissertação. Contrariando minhas expectativas, meu orientador explicou que ainda era preciso experimentar o sistema implementado, verificar se a solução proposta realmente resolveria o problema, e investigar o que os usuários iriam dizer do sistema experienciado. Ele estava me ensinando o Empirismo (Meyers, 2017). Realizar uma experiência usando o sistema que eu havia desenvolvido me custou mais um ano de pesquisa. Criamos uma disciplina para podermos experienciar o HiperDiálogo por algumas semanas e depois comparar com os resultados obtidos na disciplina TIAE. Para minha surpresa, algumas manifestações do problema ainda ocorreram apesar do uso do mecanismo de encadeamento entre mensagens. Tive que investir alguns meses fazendo análise quantitativa e qualitativa dos dados para caracterizar e explicar porque o problema ainda ocorria - constatei que minha idealização estava equivocada. Identifiquei, também, a emergência de novos fenômenos decorrentes do uso do sistema desenvolvido na pesquisa. Contudo, naquela época eu ainda não sabia dizer se o que eu havia feito era um Experimento, um Estudo de Caso ou outra coisa, e, para fugir dessas classificações, disse que havia feito uma "Avaliação". Saí pela tangente, mas estava ciente de que precisaria estudar mais sobre como fazer pesquisa científica. Apesar dessas limitações, ganhei prêmio de melhor dissertação no SBIE de 2002.

Em 2002, comecei o doutorado. Para minha surpresa, não encontrei, no curso, uma disciplina específica sobre metodologia de pesquisa. Depois constatei que muitos cursos de pós-graduação em Computação não ofertam disciplinas de metodologia, nem sobre epistemologia, filosofia e história da ciência. Minha dificuldade não era pessoal; naquela época, havia pouca discussão sobre como fazer pesquisa em computação, ao menos sobre o tipo de pesquisa que eu havia me proposto a realizar. Foi a professora Ana Maria Nicolaci da Costa, numa disciplina que cursei no Departamento de Psicologia, que me ensinou a realizar pesquisas com base em entrevistas utilizando o método que ela estava desenvolvendo, denominado Método de Explicitação do Discurso Subjacente - MEDS (Nicolaci-da-Costa, 2007). Foi uma disciplina perturbadora para mim, pois falava de subjetividade. Ela, muito firmemente, explicou que se eu fosse a campo com hipóteses a serem confirmadas ou refutadas, eu já teria estragado toda a pesquisa. Não ter hipóteses? $\mathrm{O}$ que ela me pedia era contrário às minhas práticas de pesquisa até então. Fui compreendendo o método, fiz meu roteiro de entrevista semiestruturado, depois entrevistei os alunos de uma turma a distância sobre o que eles acharam do uso de bate-papo na educação, analisei o discurso produzido nas entrevistas, e publiquei os resultados no WIE (Pimentel, Fuks e Lucena, 2003), meu primeiro artigo em que havia investigado a subjetividade. Fiquei encantado com todo aquele poder de investigação: pela primeira vez, estava conversando em profundidade com os usuários do sistema desenvolvido e produzindo conhecimento sem ficar medindo coisas.

Poucos meses depois de meu doutoramento, passei num concurso e ingressei em 2006 na universidade em que trabalho atualmente. Em 2007, iniciamos a primeira turma de nosso Programa de Pós-Graduação em Informática com ênfase em Sistemas de 
Informação (SI). Enquanto professor-pesquisador-orientador de pesquisas em SI, senti necessidade de superar urgentemente minhas limitações em termos de metodologia de pesquisa científica. Estudei em mais profundidade, e pratiquei junto com os mestrandos que começava a orientar, o método Estudo de Caso (Yin, 2005) e também Experimento (Wainer, 2007). Aprendi Pesquisa-ação ao apoiar uma amiga em sua tese. Ao participar de uma banca, pude conhecer mais sobre Netnografia; em outra, aprendi mais sobre Survey; e assim fui ampliando meu repertório de métodos de pesquisa e me formando melhor.

Considero ter me apropriado de métodos de pesquisas científicas durante a década de 2000. Nessa mesma década, acompanhei o amadurecimento do SBIE e do WIE com a crescente cobrança de que os artigos apresentassem estudos empíricos com o emprego de métodos de pesquisa científica. Hoje, nas chamadas para a submissão de artigos nesses eventos, está explicitado: "Os trabalhos devem demonstrar a qualidade acadêmica avaliada pela solidez da metodologia utilizada, pela qualidade/profundidade da fundamentação teórica e pela qualidade/profundidade da análise e da discussão dos resultados" (CBIE, 2017). Estava em paz achando que já sabia orientar pesquisas com qualidade e rigor, até que...

\section{Design Science Research: finalmente uma epistemologia para produzir conhecimento científico por meio do desenvolvimento de artefatos!}

No início da década de 2010, Flávia Santoro, minha colega de trabalho, ao retornar de seu pós-doutorado no exterior, apresentou-me o paradigma epistemológicometodológico Design Science Research - DSR (Hevner e Chatterjee, 2010; Dresch et al., 2015). Ela relatou que esse paradigma estava se popularizado na área de Sistemas de Informação. Imediatamente compreendi o porquê: é uma abordagem que legitima o desenvolvimento de artefatos como um meio para se produzir conhecimentos científicos do ponto de vista epistemológico e filosófico (principalmente a partir da obra de Hebert Simon [1969]). Finalmente uma abordagem que resolvia meu dilema sobre a confusão entre o desenvolvimento técnico e o científico em nossa área.

Na Figura 1, apresento o mapa que elaborei, com base em Wieringa (2014) e Hevner e Chatterjee (2010), para explicar aos pós-graduandos que oriento quais são os principais elementos de uma pesquisa em DSR. Nessa abordagem, um artefato é projetado para resolver algum problema num dado contexto a partir de conhecimentos e conjecturas sobre o mundo; e o uso do artefato, por sua vez, é o que possibilita avaliar as conjecturas que direcionaram seu desenvolvimento, o que nos possibilita produzir conhecimento sobre o mundo (ciência). 


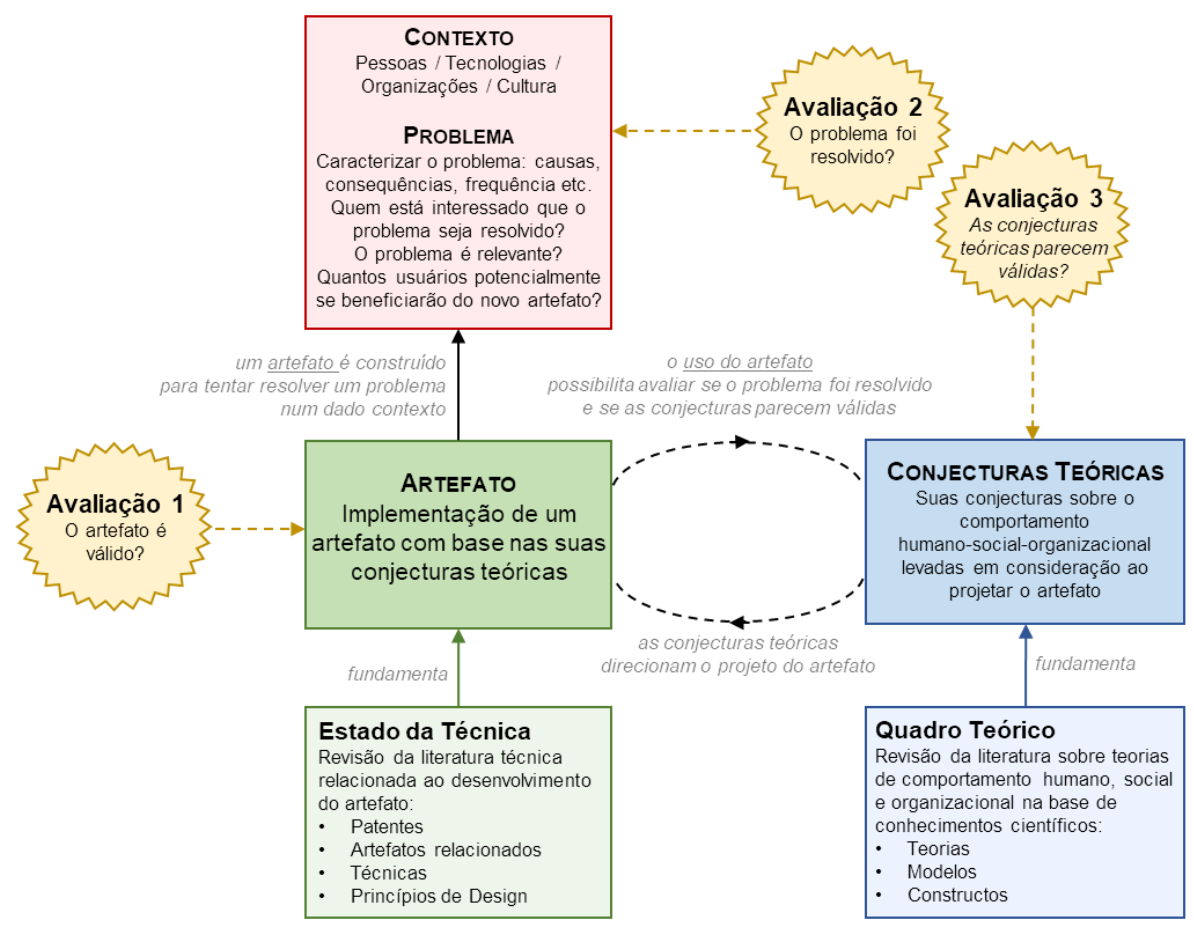

Figura 1. Mapa dos elementos que caracterizam uma pesquisa em DSR

Antes de me apropriar de DSR, nas pesquisas que orientei e realizei, muitas vezes investigávamos apenas se o artefato era válido, isto é, se parecia estar correto (Avaliação 1 da Figura 1), por exemplo, por meio de um teste de usabilidade ou investigando se os usuários compreendiam o artefato proposto. Eventualmente conseguíamos investigar também se o artefato diminuía o problema no contexto real para o qual havia sido projetado (Avaliação 2 da Figura 1). Não era muito evidente a necessidade de avançarmos com o conhecimento em termos teóricos, e nem sempre realizávamos uma reflexão sobre as conjecturas que havíamos feito e de outras contribuições para o corpo de conhecimento teórico (Avaliação 3 da Figura 1). A abordagem DSR explicita essas demandas e mostra como inter-relacioná-las em uma pesquisa aplicada e empírica que envolva o desenvolvimento de um artefato sem, com isso, perder de vista o avanço do quadro teórico que fundamenta a pesquisa. Fico com a impressão de que a abordagem DSR complexifica muito as nossas pesquisas; por outro lado, fico com mais segurança de estar fazendo realmente uma pesquisa que reconheço como científica, e não meramente um desenvolvimento técnico.

Com a dissertação de Thiago M. Santos conseguimos resultados mais alinhados ao modo DSR de produzir conhecimento. Publicamos essa pesquisa no WIE (Santos, Filippo e Pimentel, 2015), que nos rendeu prêmio de melhor artigo e por isso fomos convidados a submeter uma versão expandida para a revista RBIE (Santos, Pimentel e Filippo, 2016). Publicamos também essa pesquisa em uma revista da Educação (Pimentel, Filippo e Santos, 2015). Por fim, essa pesquisa nos rendeu o prêmio de melhor dissertação de Informática na Educação no SBIE de 2016. Ficamos entusiasmados, ainda mais porque a avaliação que realizamos nessa pesquisa foi qualitativa e com perspectiva Interpretativa, colocando o pesquisador como participante, 
realizando observação direta, grupo focal e entrevista com os sujeitos envolvidos no estudo de campo feito em escolas públicas (contexto real). O prêmio nos surpreendeu e mostrou que a área estava receptiva também para outras abordagens epistemológicasmetodológicas para além do Positivismo. Não paramos mais... agora, quase todas as pesquisas do grupo são pensadas na perspectiva epistemológica DSR, como exemplificam as posteriores dissertações do grupo.

\section{Pesquisas com os Cotidianos Escolares: adeus ao Positivismo...}

Foi também durante a década de 2010, em função do contato que vinha estabelecendo com os pesquisadores do programa de pós-graduação em Educação da UERJ (nota 7 na CAPES), que conheci a epistemologia das Pesquisas nos/dos/com os Cotidianos Escolares (Alves, 2001, 2008). Não posso dizer que foi amor à primeira vista; foi perturbador, causou-me estranhamento. Convidado para compor a banca de mestrado da Raquel Colacique (2013), ao ler sua dissertação, cheguei ao ponto de chorar. Não sabia que um relato de pesquisa científica poderia me emocionar. Quem foi que disse que não podia?

Nilda Alves $(2001,2008)$ propôs 5 movimentos que os pesquisadores devem realizar ao pensarfazer as pesquisas com os cotidianos escolares, o que vem movimentando nosso grupo de pesquisa desde meados da década de 2010 .

O primeiro movimento é denominado "sentir o mundo", que indica que o pesquisador precisa mergulhar no cotidiano escolar com todos os sentidos. Nessa abordagem, o pesquisador não realiza estudos em laboratórios, não investiga o uso do artefato por meio de testes controlados para a realização de tarefas artificiais como tipicamente se pratica em nossa área ainda predominantemente positivista. $\mathrm{O}$ que essa abordagem propõe é que o pesquisador vivencie as experiências na pele, atento ao que dizem e sentem os praticantes, seus valores e práticas culturais. Esse movimento não causou muito estranhamento em nosso grupo de pesquisa, pois já realizávamos Estudos de Caso, em que se pesquisa um fenômeno real no contexto em que ocorre, e não num laboratório. Contudo, em nosso grupo também realizávamos algumas pesquisas seguindo o método Experimento em laboratório, com dados apenas quantitativos, tentando controlar, abstrair e generalizar tudo - hoje considero que a perspectiva Positivista é, no mínimo, muito limitadora, como aponta Nilda Alves (2001, p.13): "Se continuo somente 'olhando do alto', como os que têm poder, vou compreendê-lo [o cotidiano escolar] muito limitadamente, é preciso reconhecer." Considerando esse movimento, nosso grupo resolveu abraçar a perspectiva Interpretativa, de abordagem subjetiva, operacionalizada pelos etnométodos, e abandonar de vez o Positivismo. Estamos cientes das dificuldades que enfrentaremos em nossa comunidade, pois na computação o Positivismo e o método Experimento ainda são frequentemente apresentados como sendo "o método científico", sendo invisibilizadas todas as demais epistemologias e suas abordagens metodológicas. Resolvemos assim encarar esse desafio como uma oportunidade de fazermos diferente e fazermos a diferença.

O segundo movimento é intitulado "Virar de ponta cabeça". Muitas pesquisas partem de teorias que fornecem categorias, conceitos e noções para interpretar os fenômenos. Ao mesmo tempo em que os pressupostos teóricos nos ajudam a interpretar a realidade, eles também limitam nossa capacidade de interpretação, e nem sempre 
reconhecemos a teoria como uma limitação. Entendemos esse movimento, em nosso grupo, como uma demanda por teorizarmos mais em nossas pesquisas (o que nem sempre fazíamos) sem, contudo, nos restringirmos às categorias prévias de análise para compreendermos os usos dos artefatos que projetamos em nossas pesquisas. Esse é um princípio que o método MEDS (Nicolaci-da-Costa, 2007) também já havia nos ensinado, pois naquele método adota-se a abordagem êmica: os discursos são analisados para fazer emergir categorias a partir das falas dos entrevistados.

O terceiro movimento, caracterizado como "beber de todas as fontes", refere-se a apoiar-se em múltiplas fontes de dados e conhecimentos para enfrentar a complexidade do cotidiano pesquisado. Desse movimento compreendemos, por exemplo, que devemos apresentar as falas dos sujeitos de nossas pesquisas na mesma horizontalidade que as dos teóricos, e não numa relação de subordinação para apenas ilustrar uma categoria teórica prévia. Compreendemos, também, a possibilidade de dialogarmos com outras fontes de conhecimentos em nossa cultura e não apenas com os textos científicos.

O quarto movimento intitula-se "narrar a vida e literaturizar a ciência". Por "narrar a vida", entendemos a ação de falar/explicar/analisar as experiências que o pesquisador vivencia no cotidiano, trazendo para o relato as narrativas, as conversas, as imagens e os sons produzidos nos acontecimentos. Por "literaturizar a ciência", entendemos como um movimento estético de produzir um texto que seja mais prazeroso de ser lido, dialógico e pessoal, assumidamente não-neutro; e também um movimento político, visando tornar nossos textos acadêmicos mais acessíveis a professores e técnicos que eventualmente se dispuserem a ler nossos relatos. Raquel Colacique (2013) havia narrado belissimamente sua vida e literaturizado o relato de sua pesquisa, o que explica a emoção que senti ao ler aquela dissertação. É esse o movimento que faço no presente artigo ao narrar minha vida e tentar literaturizar a ciência que estou aqui produzindo.

O quinto movimento refere-se à "presença necessária e obrigatória dos praticantespensantes dos cotidianos como seus criadores" (Ferraço et al., 2017, p.16). Em nosso grupo de pesquisa, compreendemos esse movimento como sendo uma busca pela valorização dos professores e estudantes que fazem uso dos artefatos que projetamos em nossas pesquisas - uma opção política e ética. Esse movimento já estava em minha práxis de pesquisa desde a época do mestrado, quando meu orientador solicitou investigar o que os estudantes achavam do sistema computacional que eu havia desenvolvido. Parece óbvio, não? Não, não é. Algumas pesquisas em computação não envolvem os humanos; algumas pesquisas com a aplicação da informática na Educação também não. Nem sempre os pesquisadores se interessam pelo que os professores e alunos têm a dizer sobre o artefato projetado. Em nosso grupo de pesquisa, sempre estivemos sensibilizados para a necessidade de compreendermos os usuários como praticantespensantes, e combatemos a noção sarcástica de que "o usuário é burro", muito difundida entre os desenvolvedores de sistemas computacionais, que desvaloriza a opinião dos usuários. Em nosso grupo de pesquisa, sempre nos interessamos em investigar os usos que alunos e professores fazem dos sistemas computacionais que implementamos, nos importamos com o que os usuários realmente têm a dizer sobre o artefato desenvolvido. Acho que aprendi isso com o princípio da "livre escuta" que fundamenta o método de entrevista que já havia praticado em meu doutoramento. 
VI Congresso Brasileiro de Informática na Educação (CBIE 2017)

Anais do XXVIII Simpósio Brasileiro de Informática na Educação (SBIE 2017)

\section{Considerações finais: lições aprendidas e alguns encaminhamentos}

Pesquisas com os Cotidianos Escolares e Design Science Research são abordagens de pesquisa ainda pouco conhecidas na Computação, em que, mesmo nas pesquisas de Informática na Educação, ainda predominam as pesquisas positivistas. $O$ que precisamos nos perguntar: é adequado fazer pesquisas sobre informática na educação do ponto de vista de um laboratório, sem estar efetivamente imerso no cotidiano escolar?

Medições objetivas de uma realidade exterior, embora tenham tido grande êxito na produção do conhecimento e no desenvolvimento de técnicas, podem ser problemáticas quando endereçamos questões que envolvem tecnologia, pessoas e organizações. Diferente de matérias inanimadas, componentes químicos e material biológico, as pessoas muitas vezes não reagem da mesma maneira após a realização de um experimento científico; ou seja, elas aprendem com o experimento e mudam seus comportamentos. Além disso, as pessoas e os sistemas de informação não podem ser facilmente separados do seu contexto para realização de pesquisas em laboratório. Desse modo, as abordagens interpretativas podem ser mais eficazes para se produzir conhecimento relevante a partir da investigação de sistemas de informação inseridos nas organizações e na sociedade, bem como no contexto educacional.

Devemos interrogar o que os usuários acham do sistema experienciado, como aquele sistema computacional modifica as práticas dos atores e as relações entre eles, que fenômenos emergem com o uso do sistema, o que precisa melhorar, dentre outros aspectos cuja complexidade não pode ser reduzida a um único número. Em nosso grupo de pesquisa, temos buscado compreender os sistemas computacionais como artefatos sociotécnicos (e não apenas técnicos), usados por professores e alunos num dado contexto, e por isso conversamos com os usuários por meio de conversas livres, entrevistas ou grupo focal, realizamos observação direta das pessoas usando o sistema computacional em suas atividades cotidianas reais, e interagimos com os usuários para juntos compreendermos o artefato projetado. Precisamos interpretar (em vez de medir) os discursos produzidos pelos usuários e suas ações praticadas (registradas em anotações, vídeo ou log do uso do sistema).

À primeira vista, a abordagem Cotidianista pode parecer incompatível com DSR, já que DSR “tende a ser positivista” (Lima et al., 2014, p.13). Contudo, entendemos que essa tendência é decorrente da tradição da área de pesquisa em computação, e não da abordagem epistemológica DSR, pois essa epistemologia não pressupõe que as avaliações sobre o uso do artefato sejam objetivas, quantitativas, fundadas no Positivismo. DSR pressupõe a produção de conhecimentos em contextos reais (em vez de laboratórios e situações artificiais) e específicos (não facilmente generalizáveis, nem livre de contexto), com base na autoria criatividade do pesquisador que projeta artefatos (em vez da neutralidade e afastamento entre pesquisador e o objeto de pesquisa). Nosso grupo, em vez de acreditarmos numa "tendência positivista", questionamos se a perspectiva Positivista é compatível com a epistemologia DSR. Compreendemos que a Pesquisa com os Cotidianos Escolares, por exigir o mergulho no cotidiano investigado (contexto), apresenta-se mais afinada aos pressupostos de DSR, e por isso temos operacionalizado a bricolagem entre essas abordagens nas pesquisas de nosso grupo, o que tem se mostrado adequado para fazerpensar pesquisas rigorosas, úteis e relevantes em Informática na Educação. 
Com este artigo, espero ter ressaltado a importância de discutirmos os pressupostos epistemológicos-metodológicos de nossas pesquisas nos relatos submetidos aos eventos científicos da área, pois essa discussão tem potencial para aumentar a qualidade e a relevância de nossas pesquisas. Com essa iniciativa, espero contribuir para apoiar nossa comunidade de pesquisadores em computação atuantes em Informática na Educação a entrar na década de 2020 mais amadurecida.

\section{Referências}

Alves, N. (2001) Decifrando o pergaminho: o cotidiano das escolas nas lógicas das redes cotidianas. In: Pesquisa no/do Cotidiano das Escolas: sobre redes de saberes. I. Oliveira e N. Alves (Ed.). Petrópolis/RJ: DP\&A, p. 13-38.

Alves, N. (2008) Sobre movimentos das pesquisas nos/dos/com os cotidianos. In: Pesquisa nos/dos/com os cotidianos das escolas. I. Oliveira e N. Alves (org). Petrópolis/RJ: DP\&A, p. 39-48.

Becker, H. (1986) Biographie et mosaïque scientifique. Actes de la Recherche en Sciences Sociais, n.62/63, p.105-110.

Colacique, R. (2013) Acessibilidade para surdos, na cibercultura: Os cotidianos nas redes e na educação superior online. Dissertação (Mestrado em Educação), UERJ.

Dresch, A., Lacerda, D. P., Antunes Jr, J. A. V. (2015) Design Science research: método de pesquisa para avanço da ciência e tecnologia. Porto Alegre, Bookman.

Ferraço, C.E., Soares, M.C.S., Alves, N. (2017) Michel de Certeau e as pesquisas nos/dos/com os cotidianos em educação no Brasil. Pedagogia y Saberes, n.46, Universidad Pedagógica Nacional, Facultad de Educación, p.7-17.

Ferraroti, F. (1983) Histoires et histoires de vie. Paris: Méridiens.

Fuks, H., Gerosa, M.A., Lucena, C.J.P. (2001) Sobre o desenvolvimento e aplicação de cursos totalmente a distância na Internet. In: Revista Brasileira de Informática na Educação - SBC, n. 9, set., p. 61-75.

Hevner, A., Chatterjee, S. (2010) Design Research in Information Systems: theory and practice. Springer.

Lima, S.H.O. et al. Design Science: Perspectivas Paradigmáticas e Comparações com Estudo de Caso e Pesquisa-Ação. In: VII Encontro de Estudos Organizacionais da ANPAD. Gramado - RS: ANPAD, 2014.

Macedo, R.S. (2006) Etnopesquisa crítica, etnopesquisa-formação. Brasília: Liber Livro.

Meyers, R.G. (2017) Empirismo. Petrópolis, RJ: Vozes.

Nicolaci-da-Costa, A.M. (2007) O campo da pesquisa qualitativa e o Método de Explicitação do Discurso Subjacente (MEDS). Psicol. Reflex. Crit. [online], vol.20, n.1, p.65-73.

Pimentel, M., Filippo, D., Santos, T. M. (2015) Projetando o futuro da educação com computação ubíqua. Educação \& Imagem (UERJ), v. 5, p. 1-4. 
VI Congresso Brasileiro de Informática na Educação (CBIE 2017)

Anais do XXVIII Simpósio Brasileiro de Informática na Educação (SBIE 2017)

Pimentel, M., Fuks, H., Lucena, C.J.P. (2003) Debati, debati... aprendi? Investigações sobre o papel educacional das ferramentas de bate-papo. In: IX Workshop de Informática na Escola - WIE/SBC, v. 5. Campinas, SP: Unicamp. p. 167-178.

Pimentel, M., Sampaio, F.F. (2002) Comunicografia: uma metodologia para análise de processos de interação que se desenvolvem nas ferramentas de comunicação textual da Internet utilizadas no contexto de Educação a Distância. Revista Brasileira de Informática na Educação, Porto Alegre, RS, v. 10, n.1, p. 53-59.

Pimentel, M. (1998) Brincando de Geometria com Caco e Bia. In: IV Workshop de Informática na Escola - WIE/SBC, 1998, Belo Horizonte - MG. XXV SEMISH/XI CTD/XVII CTIC/VI WEI/IV WIE. Belo Horizonte - MG: SBC. p. 631.

Pimentel, M., Souza, T.P. (1996) AlgGraf: Ambiente Educacional aplicado a Algoritmos e Grafos. In: VII Simpósio Brasileiro de Informática na Educação SBIE/SBC, 1996, Belo Horizonte - MG. VII Simpósio Brasileiro de Informática na Educação - SBIE/SBC. Belo Horizonte - MG: UFMG. p. 15-27.

PROVA de conceito. In: Wikipédia: a enciclopédia livre. Disponível em: $<$ https://pt.wikipedia.org/wiki/Prova_de_conceito> Acesso em: 10 jun 2017.

RBIE - Revista Brasileira de Informática na Educação. Disponível online: $<$ http://www.br-ie.org/pub/index.php/rbie/index>. Acesso em: 30 jun 2017.

Sampaio, F.F., Pimentel, M. (2000) Comunicografia: uma metodologia para análise de processos de interação que se desenvolvem nas ferramentas de comunicação textual da internet utilizadas no contexto de educação a distância. In: XI Simpósio Brasileiro de Informática na Educação - SBIE/SBC, Maceió - AL: UFAL. p. 83-96.

Santos, T.M, Filippo, D., Pimentel, M. (2015) Computação Ubíqua para apoiar a educação musical: explorações com o Makey Makey. In: XXI Workshop de Informática na Escola, Maceió. v. 1. p. 330-339.

Santos, T.M.. Pimentel, M., Filippo, D. (2016) Tapetes Musicais Inteligentes: Computação Ubíqua para apoiar a Educação Musical. Revista Brasileira de Informática na Educação, v. 24, p. 123-142.

SBIE - Congresso Brasileiro de Informática na Educação. Disponível online: $<$ https://sabertecnologias.com.br/cbie/index.php/eventos-paralelos-esubmissoes/sbie/>. Acesso em: 30 jun 2017.

Simon, H.A. (1969) The sciences of the artificial. Cambridge: MIT Press.

Wainer, J. (2007) Métodos de pesquisa quantitativa e qualitativa para a ciência da computação. In: Jornada de Atualização em Informática (SBC/JAI), p. 221-262.

Wazlawick, R.S. (2008) Metodologia de pesquisa para ciência da computação. Rio de Janeiro: Elsevier.

Wieringa, R.J. (2014) Design Science Methodology for Information Systems and Software Engineering. Springer.

Yin, R.K. (2005) Estudo de caso: planejamento e métodos. 3.ed. Porto Alegre: Bookman. 